\title{
Differential power as a metric to optimize power converters and architectures
}

\author{
José A. Cobos, Helena Cristóbal, Diego Serrano, Regina Ramos, Jesús A. Oliver and Pedro Alou
}

\section{INTRODUCTION}

To our knowledge, the fundamental limits of switching mode dc-dc converters were described in [1] in 1966 and extensively ellaborated in [2] in 1969. The concepts of "dc" and "ac" power, and also "direct" and "indirect" power were described, and their fundamental limits quantified, as a function of the voltage and/or current gain of the converter. The "direct power" is the power that is transferred from the source to the load without causing any impact on the volume or losses of the components of the power converter. The "ac" or "indirect" power, accounts for the energy stored and delivered, in a switching cycle, by the reactive components to perform the power conversion. The "indirect power" is the one that determines the volume and losses of the power converter. The Two-input buck converter [3] is a clear example of how, for a given amount of "indirect power", any arbitrary level of "direct power", and hence output power, may be delivered from the two input sources to the load, just by adjusting their voltages. Some of the fundamental limits are explored and applied in [4] to compare switched capacitor (SC) topologies, concluding that the "series-parallel" converter meets the limit of "ac power" but not the "VA rating" limit, whereas the "ladder" converter meets the "VA rating" limit, but is far from the "ac power" limit. The "indirect" power has also been used in the literature [5] to propose power architectures in which voltage gain is performed by a different building block than voltage regulation, which is similar, though in reverse power flow direction, to [6].

The fundamental limits of power conversion are not extensively used in the literature, possibly because in 2-port dcdc converters, based on inductors, most traditional topologies are close to the fundamental limits, and the added value is in the optimization process, which accounts for the specific technology being used. However, we find it extremely useful not only for high level comparison of power architectures, but also for the detailed optimization of energy buffered and hybrid converters. In hybrid converters, part of the indirect power is processed by inductors, and other part is processed multiple times by capacitors. In this paper, we calculate the fundamental limit of 3-port energy buffered converter, and use this information to synthesize a specific inverter/rectifier which operates in the fundamental limit, processing half of the internal power than state of the art converters.

\section{DIRECT, INDIRECT \& DIFFERENTIAL POWER}

In this paper, we refer to "Differential Power" $\left(P_{\text {diff }}\right)$ as the minimum possible power to be processed by the components (including transformers) of a power converter for a given electrical specification, regardless of the specific circuit implementation, that is, at system level. It is the difference between the "nominal power" $\left(P_{i n} \approx P_{o}\right)$ and the "direct power" $\left(P_{\text {dir }}\right)$ as illustrated in Fig. 1.a. $P_{\text {diff }}$ is also proportional to the voltage difference between input and output, as illustrated in Fig. 1.c.

a)

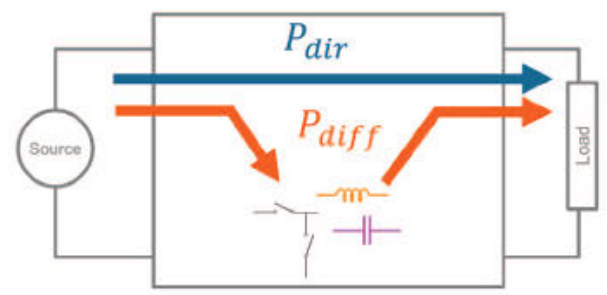

b)

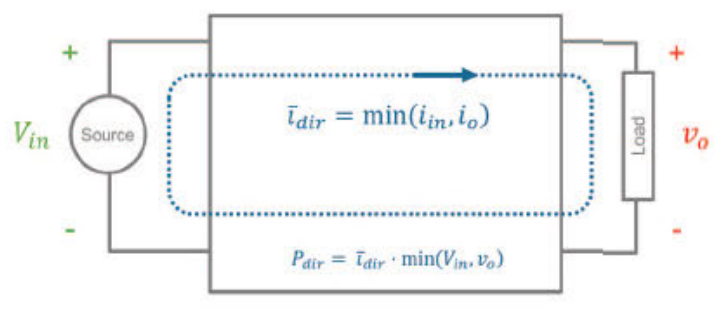

c)

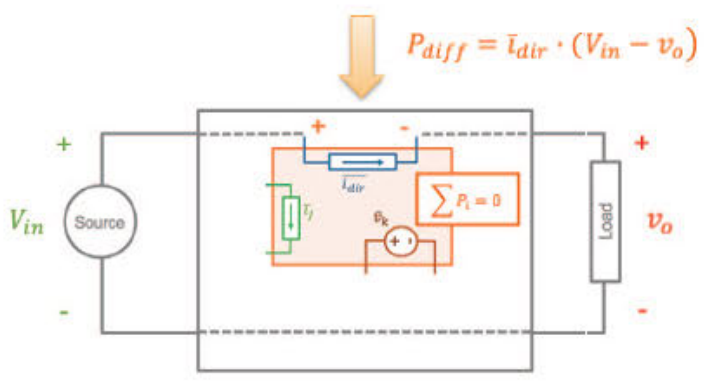

Fig. 1. "Direct" and "Differential" Power (a), "Direct averaged current" (b) and "Averaged power model" (c)
Part of the experimental results of this work were supported by the awards received from Google Inc. and ECPE to participate in the "Little Box Challenge" 

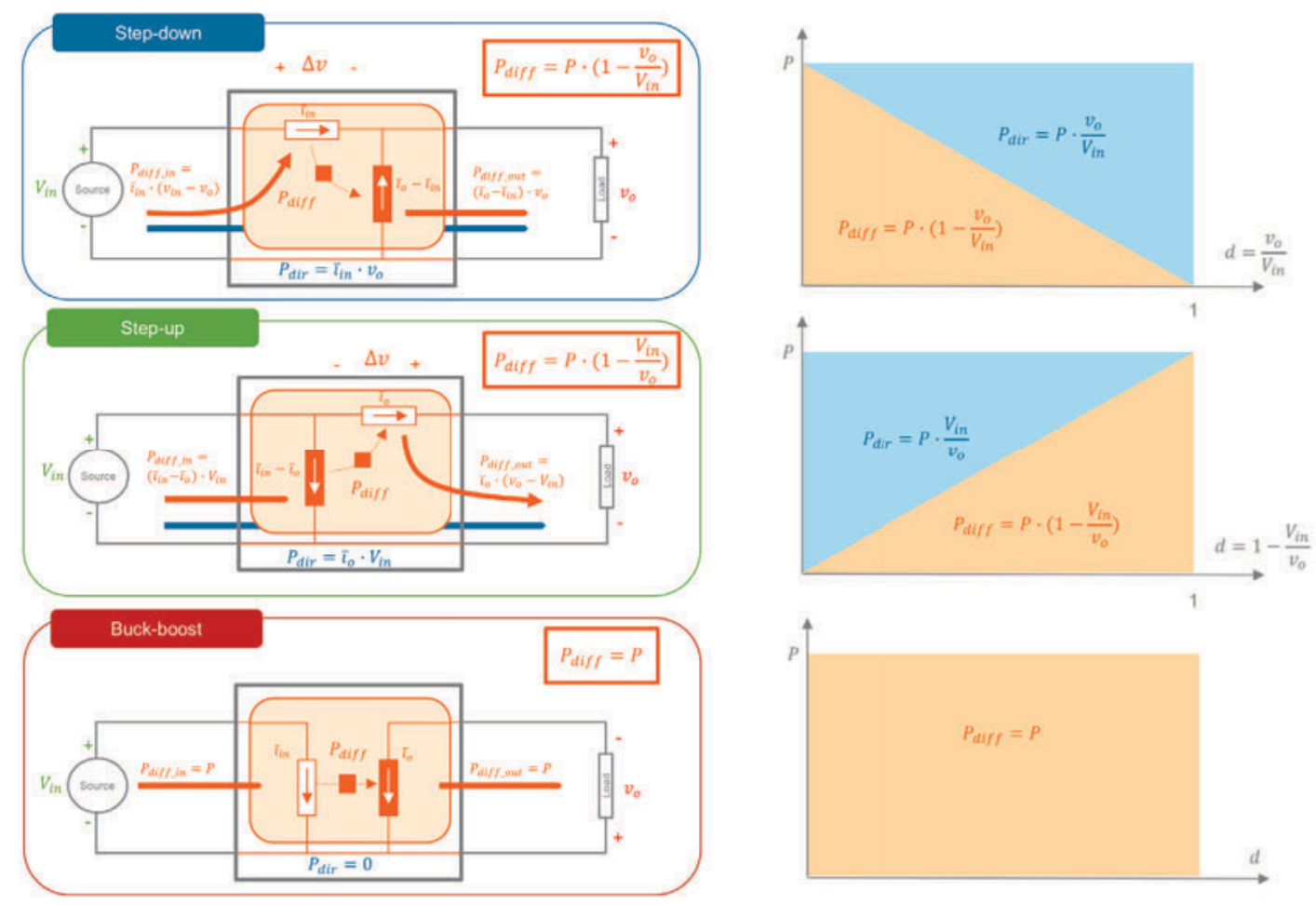

Fig. 2. "Average power models" of step-up, step down and "indirect" (or buck-boost) converters

The "direct average current" ( $\left.\bar{l}_{\text {dir }}\right)$ is the maximum possible common current, that would transfer the maximum possible "direct power" in a loop including the source and the load. That is, the minimum value of input and output currents, as illustrated in 0.b. Then, the "direct power" is the product of this current by the minimum of input and output voltages, as illustrated in (1). Consequently, $P_{\text {diff }}$ may be expressed as (2). The internal power $\left(P_{\text {int }}\right)$ processed by all the components of a power converter is in general higher than $P_{\text {diff }}(3)$, especially in isolated converters and most hybrid and SC converters. In general, the internal power is processed by inductors and capacitors, though the power processed by transformers need to be included in any design and optimization process, and in some cases, the power processed by capacitors is transferred in a resonan fashion, so it may be accounted for separately, as illustrated in (4).

$$
\begin{gathered}
P_{d i}=\imath_{d i} \quad \min \left(V_{i n}, v_{o}\right) \\
P_{d i f f}=l_{d i} \quad \operatorname{abs}\left(V_{i n}-v_{o}\right) \\
P_{\text {int }} \geq P_{d i f f}=P-P_{d i} \\
P_{\text {int }}=P_{\text {int_L }}+P_{\text {int_C }}+P_{\text {int_e }}+P_{\text {int_T }}
\end{gathered}
$$

Fig. 2 illustrates the power models of the three basic families of 2-port dc-dc power converters; step-up, step-down and "indirect" or "buck-boost" type. They are implemented with current sources, but in general they can be redrawn with voltage or power sources, with the only restriction that the sum of the positive and negative powers need to be equal. For the three basic converters, the power drawn from the source by one current source $\left(P_{\text {diff }}\right)$ is delivered to the other, and then transferred to the load. This differential power, summed to the direct power, totals the output power. It can be seen in the plots that in "direct" converters, the closest the input and output voltages, the lower the differential power, and the higher the direct power. In the "indirect" converter however, the direct power is zero, and therefore the differential power is the nominal power, regardsless of the gain. The "Differential power" may be processed either by capacitors or inductors, as illustrated in Fig. 3 , with different impact on volume and losses of the converter, depending on the technology of dielectrics and magnetic materials

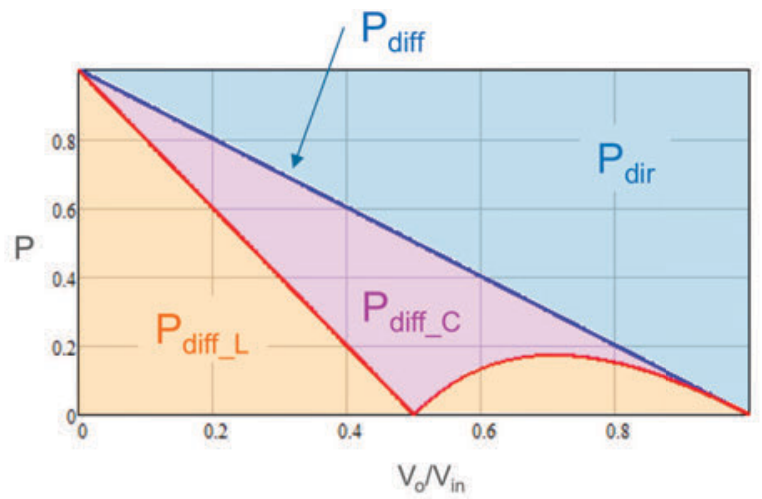

Fig. 3. "Differential" Power is processed by inductors and capacitors in a 3-level buck converter 


\section{ENERGY BUFFERED CONVERTERS}

Energy buffered power converters are those in which the input power does not match the output power, requiring internal energy storage for proper operation. Two of the most significant examples are "Power supplies with Power Factor Correction", [7] and "Single phase inverters with constant input current" [8]. In the first case, the output is dc and the input ac current is shaped to follow the sinusoidal input voltage. In the second case, the output is ac and the input current of the inverter is constant to properly operate the PV panels or batteries. Both architectures can be represented in Fig. 4, nulling some elements depending on the power flow.
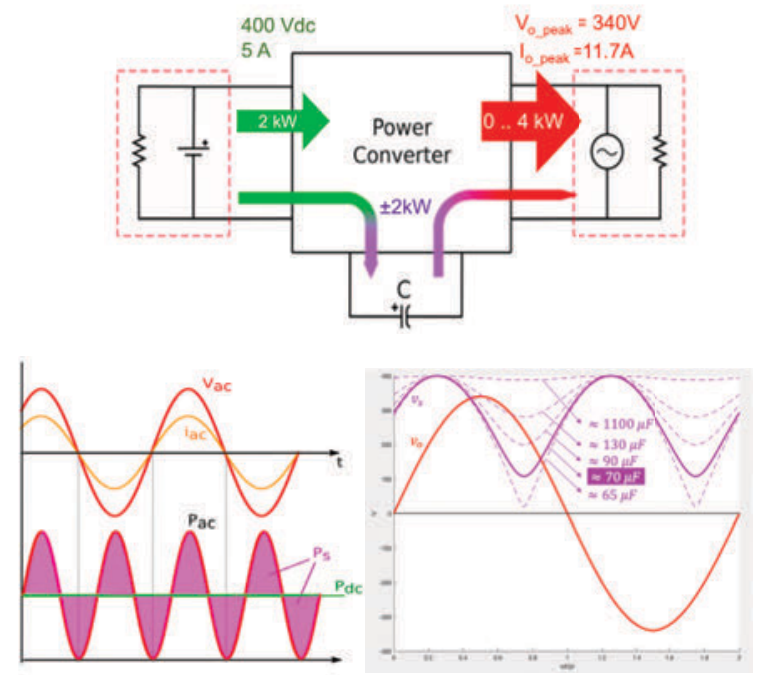

Fig. 4. Energy Buffered Power Converters

In general, it may be analyzed as a 3-port power converter without any restriction on the voltage or power waveforms, though in both applications described above, we may find three ports: $d c, a c$ and storage. In some cases, the storage port may be internal, not accessible. As illustrated in Fig. 9, pulsating power $\mathrm{P}_{\mathrm{ac}}$ in the ac port, at line frequency (typically 50 or $60 \mathrm{~Hz}$ ), does not match with the dc power, $\mathrm{P}_{\mathrm{dc}}$, therefore requiring a storage element (typically a capacitor), to balance the mismatch, $\mathrm{P}_{\mathrm{s}}$. Power may flow from the ac port to the dc port (in the case of a system with Power Factor Correction), or from the dc port to the ac port (in the case of the single-phase inverter). The capacitor, in both cases, absorbs or delivers power, $\mathrm{P}_{\mathrm{s}}$, along the line cycle to match input and output power, therefore changing its voltage, $\mathrm{v}_{\mathrm{s}}$.

\section{COMPARISON OF EBC ARCHITECTURES}

Fig. 4 includes some values of power, voltage and current levels obtained for The Little Box Challenge specification [8], which was an international competition held from Sept 2014 to October 2015, sponsored by Google Inc. and the IEEE, to achieve a 10x reduction in the volume of a single phase, non isolated, $2 \mathrm{kVA}$ inverter. The technology that would enable such reduction was the emerging use of wide bandgap (WBG) semiconductors, namely $\mathrm{GaN}$ and $\mathrm{SiC}$, in power devices, faster, smaller and more efficient than their Si counterparts. One key specification was the small ripple $(20 \%)$ allowed in the input current, which required energy buffering in the power converter. Fig. 4 also shows the voiltage in the storage capacitor for several values of $\mathrm{C}_{\mathrm{s}}$. The discharge ratio of the storage capacitor is a key parameter, affecting the volume of $\mathrm{C}_{\mathrm{s}}$ and the power stages. A large discharge ratio reduces the required volume of the capacitor but imposes high voltage gain in the power converters.

The typical methodology to build such a power inverter would be to select a short list of power architectures, as those illustrated in Fig. 5, and then run optimization algorithms to achieve the minimum possible volume for a given thermal capability, so that the external temperature of the box would not exceed 60C.

It should be noted that in some cases, additional line frequency unfolder stage may be added in the ac port, so that dc-dc instead of dc-ac converter stages may be used. In any case, the average power models described in previous sections can be used to calculate the "Differential Power" of these architectures The fact that $P_{\text {diff }}$ can be calculated for all these architectures, regardless of the specific topology used in each stage, provides a new insight in the methodology, to make high-level comparison for power architectures. It is especially important because $P_{\text {diff }}$ is directly related with volume and losses of the converter

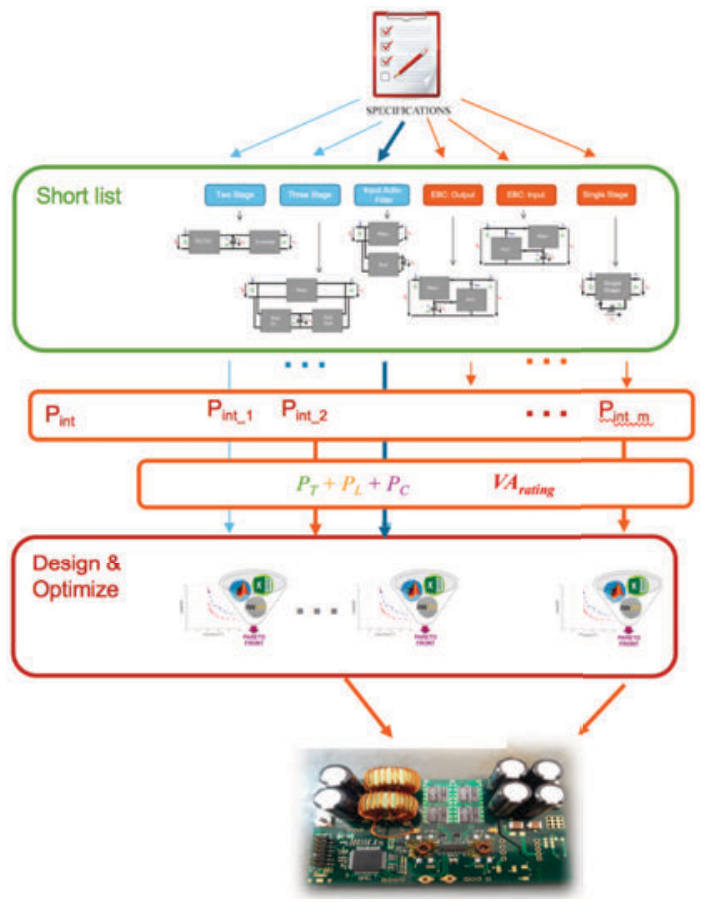

Fig. 5. Including the internal power processing in the design methodology

The calculation of $P_{\text {diff }}$ as a function of the voltage in the storage port may help to take some design decisions, both for the architecture and for the discharge ratio of the storage capacitor. It is good to know how far is our specific circuit in terms of internal power processing, $P_{\text {int }}$, from the minimum possible value, that is, from the differential power, $P_{\text {diff. }}$ Nevertheless, the next steps are the decision on whether processing the internal power, through inductors or capacitors, and to optimize the circuit for the selected technologies of semiconductors ( $\mathrm{Si}, \mathrm{GaN}$, SiC...), dielectrics (electrolytic, MLCC, Film...) and magnetic materials (ferrite, iron powder, amorphous...). 


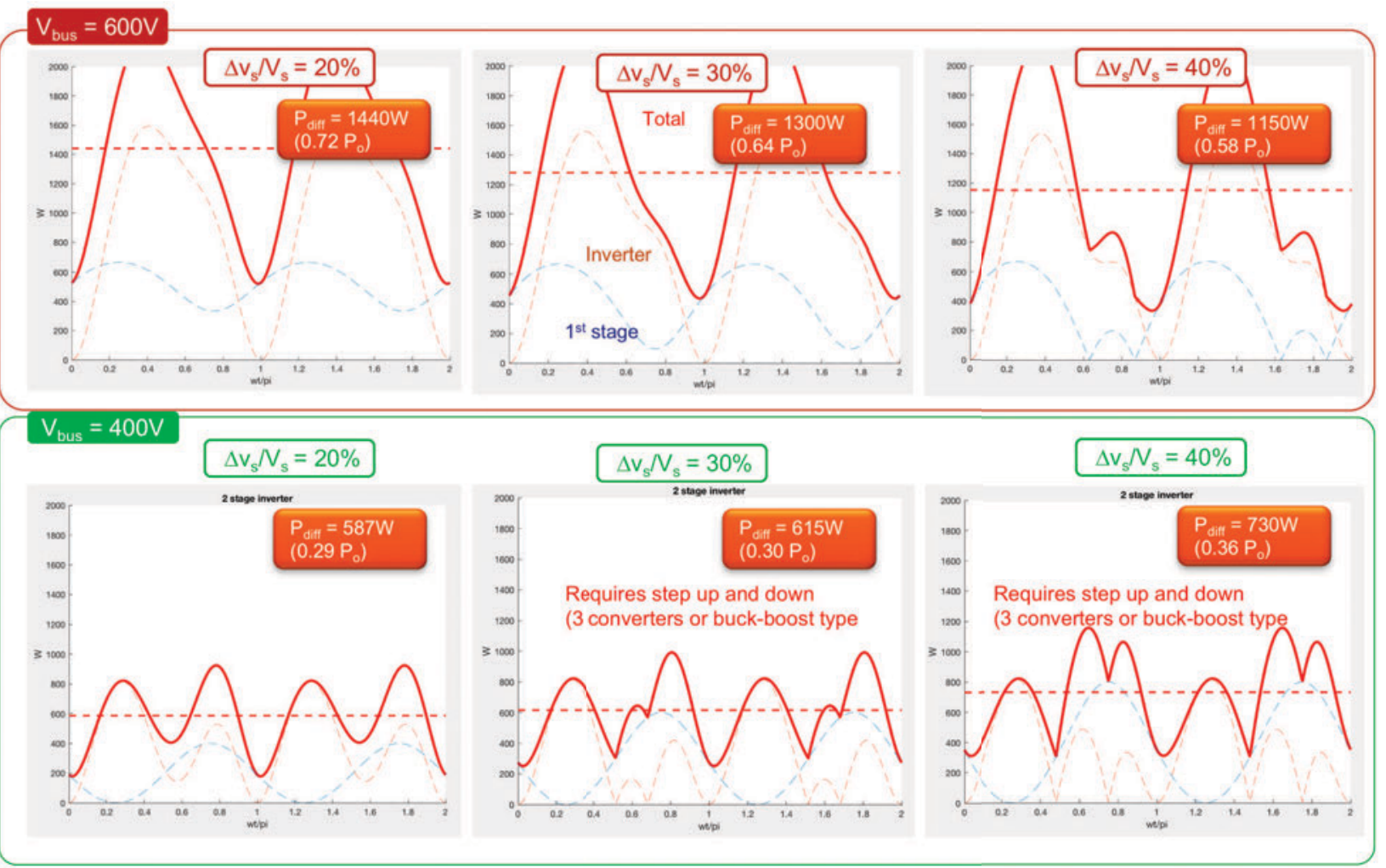

Fig. 6. Differential Power along the line cycle of "2-stage" architecture for various nominal voltages and discharge ratios of the storage capacitor
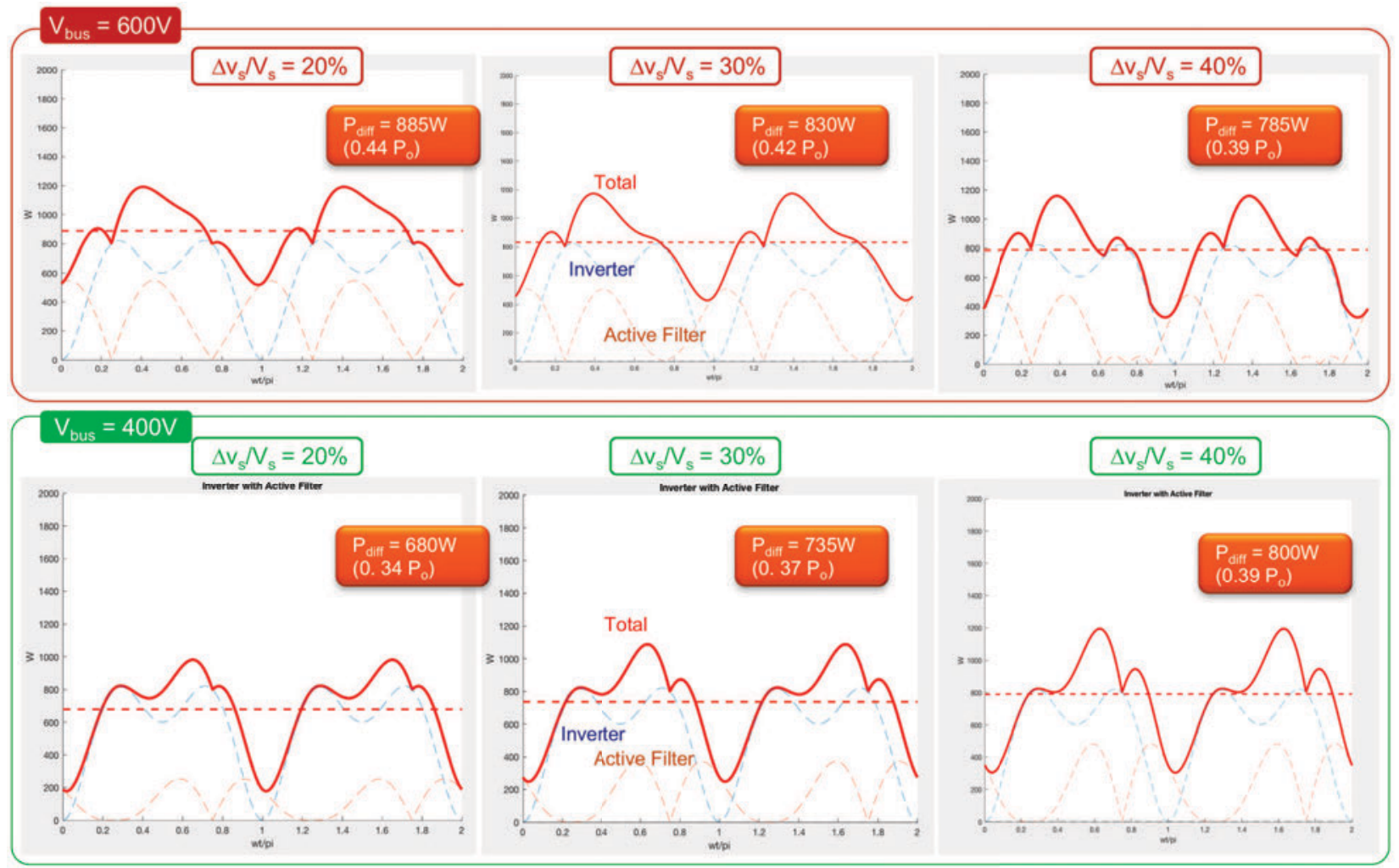

Fig. 7. Differential Power along the line cycle of "Active filter" architecture for various nominal voltages and discharge ratios of the storage capacitor 
To make the high-level comparison, the differential power is calculated at converter level, for two ranges of voltage in the storage capacitor, namely 400 and $600 \mathrm{~V}$, and for three values of the discharge ratio of the storage capacitor, namely $20 \%, 30 \%$ and $40 \%$. The result is plotted along the line cycle for both the "2-stage" and the "active filter" architectures in Fig. 6 and Fig. 7. The average value of this power (see Fig. 8) determines the average losses and temperature, for some selected components which are determined by the maximum value of the differential power along the line cycle. As could be expected, a high voltage bus requires hihg voltage conversion, which implies high differential power. However, this effect is attenuated as long as the discharge ratiom is increased, because the voltage in the storage port becomes closer to the dc and ac ports. It is very important to note that in the 2-stage approach, a large discharge ratio would require two different power stages to be able to process the minimal internal power, that is $P_{\text {diff }}$.

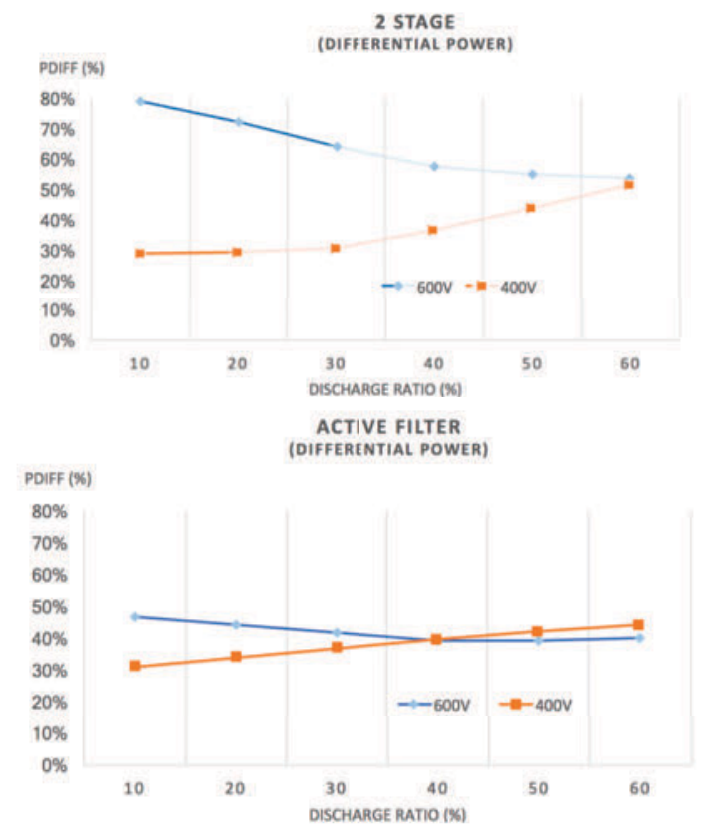

Fig. 8. Average Differential Power of "2-stage" and "Active filter" architectures for various nominal voltages and discharge ratios of $\mathrm{C}_{s}$

\section{DIFFERENTIAL POWER IN 3-PORT CONVERTERS}

The approach described above is valid and applicable to any power architecture built with 2-port building blocks. The question is whether a 3-port architecture would process lower $P_{\text {diff }}$ than an architecture based on 2-port power converters. In other words, whether a single stage topology could eventually process less power than power architectures composed by several power stages.

Although we developed the specific inverter and modulation techniques [9] prior to developing the averaged models at system level the results match well, as described in subsequent sections.

Just for the purpose of illustrating the essence of the 3-port approach, let us take as example the power conversion required at $\omega t=\pi / 2$. At this instant of the line cycle, the power required by the load is $4 \mathrm{~kW}$, which is provided by the input dc port $(2 \mathrm{~kW})$

and the storage capacitor $(2 \mathrm{~kW})$. For a storage capacitor of approximately $70 \mu \mathrm{F}$, the current provided by $\mathrm{C}_{\mathrm{s}}(6.7 \mathrm{~A})$ plus the $5 \mathrm{~A}$ current provided by the dc-port equals the output current (11.7A). In such operating conditions, which only occur for that intentionally chosen capacitance value, two power conversion processes apply: first, some charge needs to flow from a $400 \mathrm{~V}$ port to the $340 \mathrm{~V}$ output port. That is, some energy is released, that may be quantified and represented by a delivered differential power of $300 \mathrm{~W}$. In the 2-port model described in figure 2 (step-down) this power would be absorbed and delivered to the load by another current source connected to ground. There is a second process, in which some charge needs to flow from the storage capacitor (295V approx) to the load $(340 \mathrm{~V})$. It requires some energy, that again may be quantified and represented by an absorbed differential power of $300 \mathrm{~W}$. In the 2-port model described in figure 2 (step-up) this power would be previously absorbed from the source by another current source connected to the dc port. In summary, there are 2 different processes, one requires $+300 \mathrm{~W}$ and the other requires $-300 \mathrm{~W}$. This is illustrated in Fig. 9.a. The obvious question is whether both processes could be combined in a single power model as illustrated in Fig. 9.b. and later on implemented in a specific power stage. In fact, what has been described is just how the TI-buck converter operates, illustrated in Fig. 9.c. Although this is just an example valid for only a single operating point and ideal values, it is very appropriate to quantify the direct power, $P_{d i r}$, and the differential power, $P_{\text {diff. }}$. By averaging the on and off intervals of Fig. 9.d and 9.e, it can be easily calculated that the power processed by the inductor is $300 \mathrm{~W}$, the power flowing directly from the dc port to the load is $1700 \mathrm{~W}$ and the power flowing directly from the storage port to the load is $2000 \mathrm{~W}$. That is, only $300 \mathrm{~W}$ of differential power are required to deliver $4 \mathrm{~kW}$ to the load. The fact is that a power stage designed for $300 \mathrm{~W}$ may transfer "directly" other additional 3700W (without affecting volume and losses) to make a total of $4 \mathrm{~kW}$.

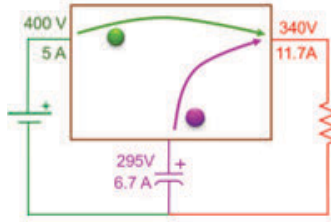

a)

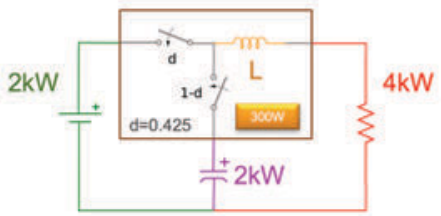

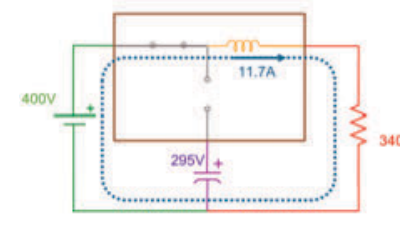

d) c)

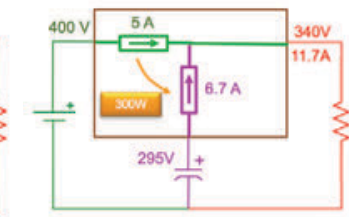

b)

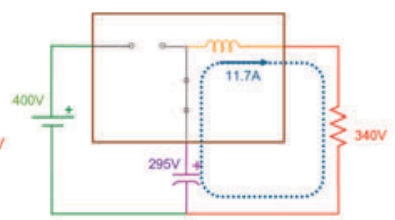

e)
Fig. 9. Two-input Buck converter processing only $300 \mathrm{~W}$ to deliver $4 \mathrm{~kW}$ to the $\mathrm{AC}$ load, at $\omega \mathrm{t}=\pi / 2$ 


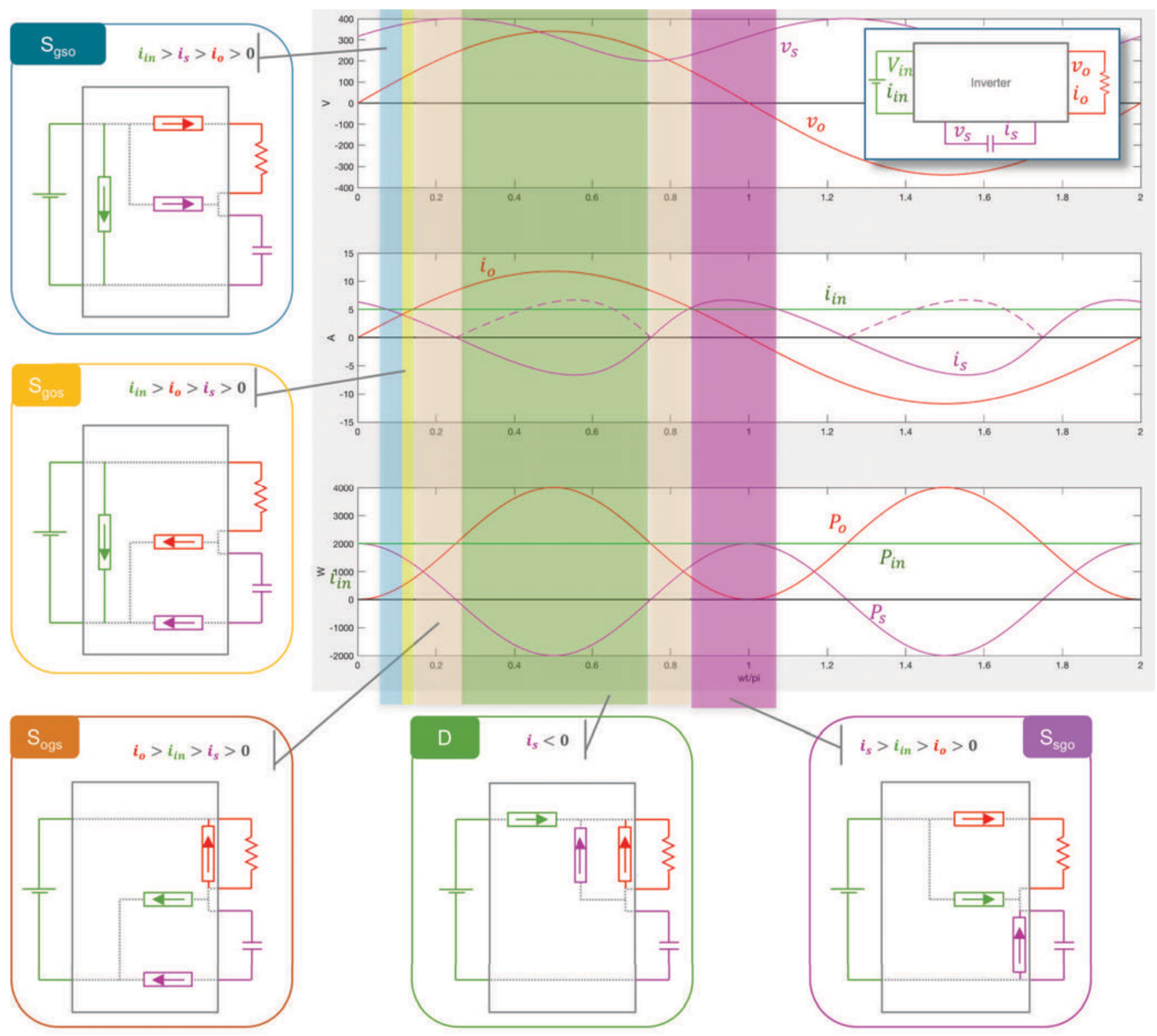

Fig. 10. Equivalent Power models along the line cycle of the 3-port single stage inverter

Fig. 10 illustrates the specific averaged power models along the line cycle proposed to minimize the internal power processing of any energy buffered converter, based on the generic 3-port model illustrated in Fig. 11

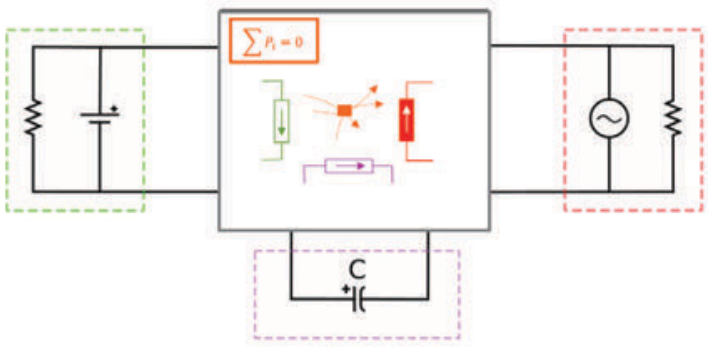

Fig. 11. Generic Power model of a 3-port converter

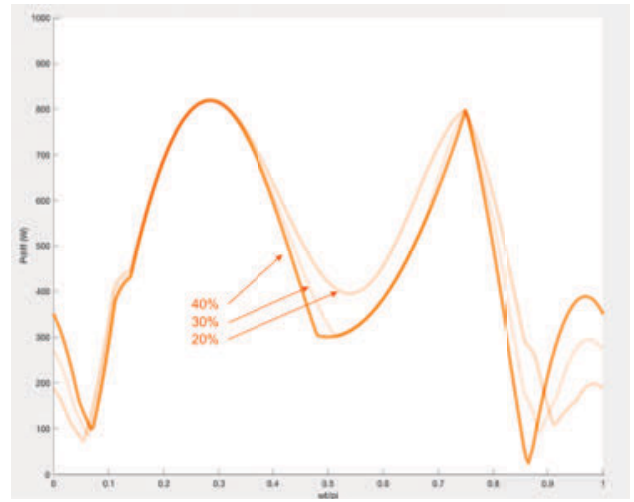

Fig. 12. $\mathrm{P}_{\text {diff }}$ of an EBC, for several discharge ratios of the storage capacitor 
The power absorbed or delivered by each individual current source is easily calculated. The sum of the 3 powers needs to be zero, being either one of them positive and the other 2 negative or vice versa. The highest absolute value is selected and plotted in Fig. 12, for any discharge ratio. This way we account for the average differential power processed by the 3-port converter, which for this specific case (the little box challenge) results in $478 \mathrm{~W}$ for a $40 \%$ discharge ratio in the storage capacitor. It is a $24 \%$ of the nominal power, which is a very good value, compared to the $39 \%(790 \mathrm{~W})$ of the active filter architecture, for the same $40 \%$ discharge ratio. It is also important to double check that at $\omega \mathrm{t}=\pi / 2$ hget differential power is just $300 \mathrm{~W}$, as described above, and that the worst case along the line cycle is not the point of maximum nominal power $(4 \mathrm{~kW})$ but the points in which the storage capacitor is neither providing nor absorbing power.

\section{SYNTHESIS OF A SINGLE STAGE INVERTER OPERATING IN THE FUNDAMENTAL LIMIT}

Although it would be good to synthesize a circuit to operate in the fundamental limit of a 3-port power converter used as an energy buffered converter, the actual process was the opposite.

The power inverter illustrated in Fig. 13.a is apparently the wellknown 3-level flying capacitor inverter [10]. However, the novelty is that the power stage is not operated to have the typical $\mathrm{V}_{\text {in }} / 2$ voltage in $\mathrm{C}_{\mathrm{s}}$, but the voltage required by the storage capacitor in Energy Buffered Converters. That is, $\mathrm{C}_{\mathrm{s}}$ is charged and discharged at line frequency so that it stores the necessary energy to balance the power at the dc and ac ports.
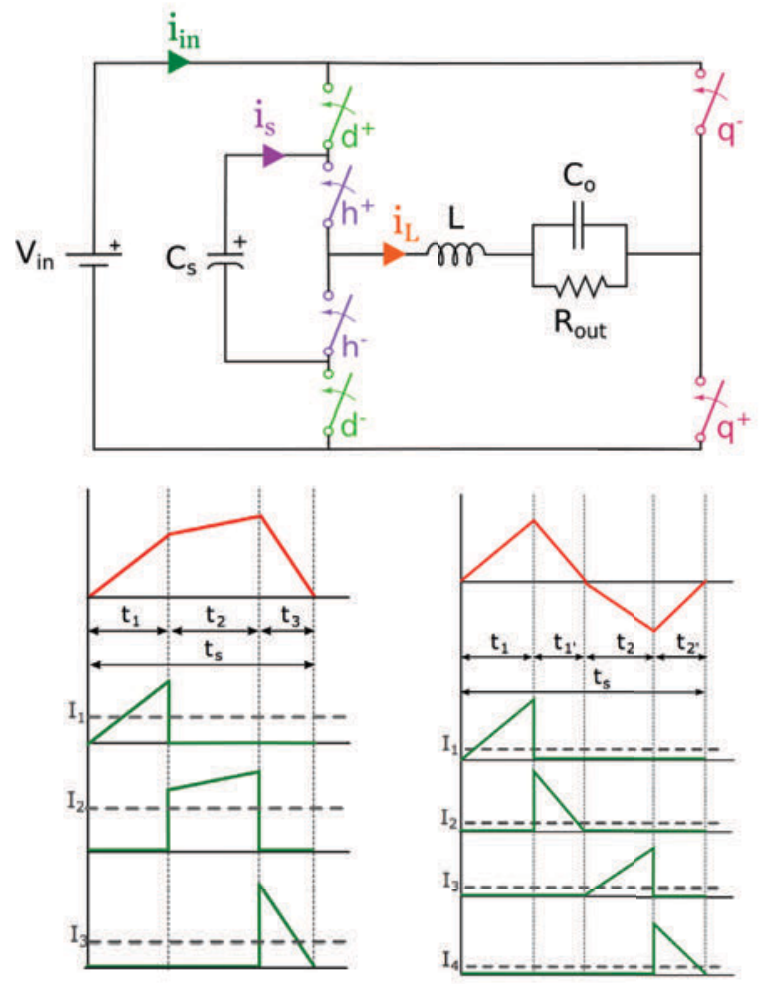

Fig. 13. 3-level single stage inverter, operated so that the flying capacitor stores the line frequency energy mismatch between the dc and ac ports
If the flying capacitor is regarded as the storage capacitor, then the inverter is composed just by 6 switches and one inductor. The inductor may be driven in 19 operation modes ( 9 of them are symmetrical for positive and negative output voltage), including triangular and trapezoidal modes, as illustrated in Fig. 13.b. although not all of them would be needed for resistive load in steady state. This way, the current in the inductor always performs at least 2 functions simultaneously, namely delivering "direct" power to the load, "charging" or "discharging" the storage capacitor, and "processing" the necessary internal power to achieve voltage regulation. Nevertheless, it should be noted that part of the "differential power" is processed during some intervals of the line cycle by the storage capacitor, acting as a flying capacitor. Also, Zero Voltage Switching (ZVS) is achieved in all switching transitions, so that switching losses are minimized.

Fig. 14 illustrates the part of the differential power processed by the inductor, which is the only reactive component of the power stage of the inverter (besides the storage and input and output capacitors)
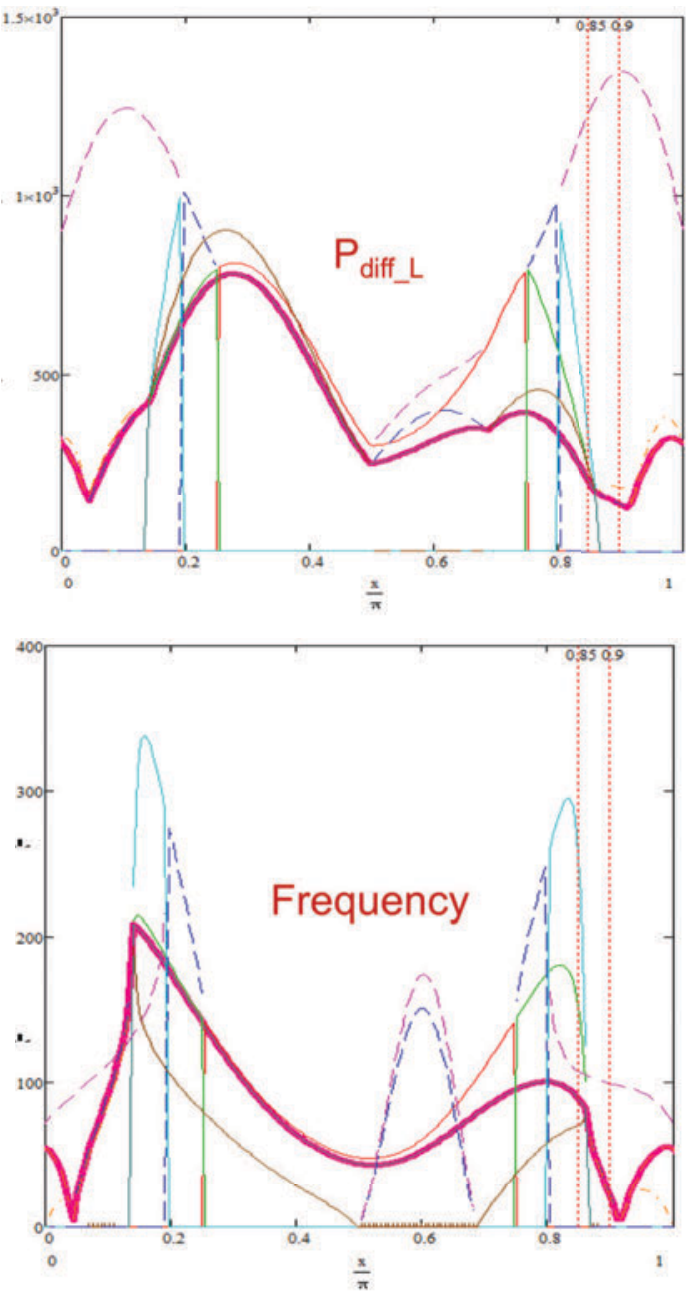

Fig. 14. Differential power processed by the inductor (top) and associated switching frequency (bottom) for each of the possible opoeration modes along the line cycle, for $30 \%$ discharge ratio of the storage capacitor and resistive load. 
The differential power processed by the inductor of the inverter is compared with the differential power calculated using the average power models, and illustrated in Fig. 15 It can be seen that the power processed by the inductor in the real circuit is very close to the fundamental limit, being below the limit in the part of the cycle that the storage capacitor behaves as a flying capacitor, participating in the high frequency power conversion.

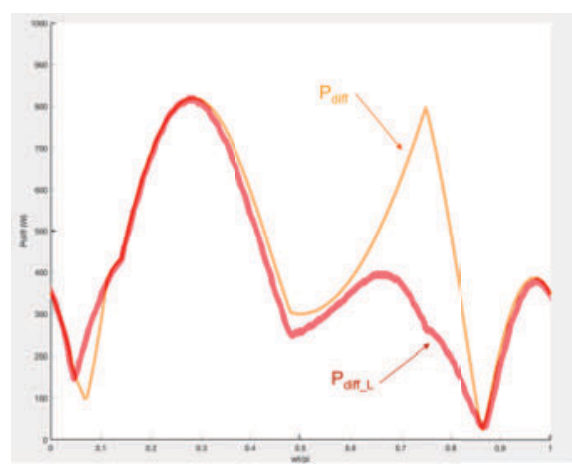

Fig. 15. Comparison of theoretical $\mathrm{P}_{\text {diff }}$ calculated with porposed average power models and the one processed by the inductor, for a $40 \%$ discharge ratio of the storage capacitor

Finally, Fig. 16 summarizes the "differential power" of the power architectures analyzed to implement an Energy buffered converter, for the Little Box Challege specification. It can be seen that the proposed single stage inverter processes internally roughly half of the power (20\% compared to $40 \%$ ) than the most widely used architecture for a $40 \%$ discharge ratio in the storage capacitor.

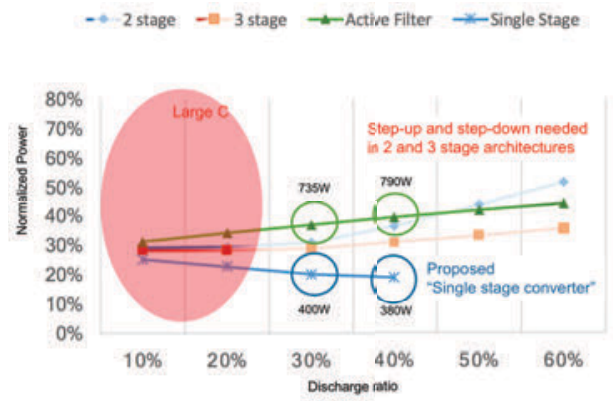

Fig. 16. Comparison of $\mathrm{P}_{\text {diff }}$ for different architectures to implement an EBC, for several discharge ratios of the storage capacitor

For the practical implementation of this multi-mode inverter, several challenges had to be addressed. The zones of existence of the different operation modes had to be defined so that a simple "mode selector" could be implemented [11]. The design of the control loops, capable of transitioning the different modes without significant perturbation was dramatically simplified implementing a plant inversion strategy [12] Some other issues in this inverter are the implementation of the control strategy in an FPGA, and the common mode noise produced as a consequence of the fast GaN devices used in the inverter. All these issues were satisfactorily solved, and final details on the losses and volume of this actual single stage inverter will eventually be provided in following publications.

\section{CONCLUSIONS}

The fundamental limits of power converters are important, not only to know how far our design is from the limits, but also to help in the optimization process, to compare different alternatives, or even to propose new power architectures.

"Differential Power" is proposed in this paper as a high-level metric to compare and optimize energy buffered converters. It accounts for the minimum internal power processed by the reactive components, which has direct impact on overall volume, losses, reliability and cost. Using this metric, the most popular architectures for energy buffered converters are compared for several voltage discharge ratios of the line frequency storage capacitor.

A novel single stage topology has been proposed, that processes roughly half of the internal power than classical architectures, $20 \%$ compared to $40 \%$ of the nominal power, with straight forward impact on losses and volume.

The fact that the differential power can be calculated for all these architectures, using the proposed average power models, both for 2-port and 3-port converters, regardless of the specific topology used in each stage, provides a new methodology to perform high-level comparison for power architectures.

\section{REFERENCES}

[1] E. T. Moore and T. G. Wilson. "Basic considerations for dc to dc conversion networks," IEEh Trans. Magn. (1966 Intermag Issue), vol. MAG-2, pp. 620-624, Sept. 1966.

[2] D. Wollaver, "Fundamental study of dc to dc conversion system," Ph.D. dissertation, Massachusetts Institute of Technology, 1969.

[3] J. Sebastián, P. Villegas, F. Nuño and M.M. Hernando, "Very efficient two-input dc-to-dc switching post-regulators", IEEE PESC'96, pp. $874-$ 880

[4] M. Seeman and S. Sanders, "Analysis and optimization of switchedcapacitor DC-DC converters," IEEE Trans. Power Electron., vol. 23, no. 2, pp. 841-851, Mar. 2008.

[5] H. Chen, K. Sabi, H.Kim, T. Harada, R. Erickson and D. Maksimović, "A 98.7\% Efficient Composite Converter Architecture with ApplicationTailored Efficiency Characteristic". IEEE-ECCE. 2014

[6] J. Sun, M. Xu. D. Reusch and F.C. Lee. "High Efficiency Quasi-Parallel Voltage Regulators". IEEE-APEC 2008.

[7] O. García, J A. Cobos, R. Prieto, P. Alou, J. Uceda. "Single phase power factor correction. A survey". IEEE Transactions on Power Electronics. 2003, Vol 18-3, 749 - 755, DOI: 10.1109/TPEL.2003.810856

[8] "Detailed Inverter Specifications, Testing Procedure, and Technical Approach and Testing Application Requirements for the Little Box Challenge"

https://www.littleboxchallenge.com/pdf/LBCInverterRequirements20141216.pdf.

[9] J. A. Cobos, "Optimization of energy buffered converters," in Power Electronics (CIEP), 2016 13th International Conference on, IEEE, 2016.

[10] T.Meynard and H.Foch,"Multi-levelconversion:highvoltagechoppers and voltage-source inverters," in Power Electronics Specialists Confer- ence, 1992. PESC'92 Record., 23rd Annual IEEE, pp. 397-403, IEEE, 1992.

[11] R. Ramos, I. Zubitur, D. Serrano, J. A. Oliver, P. Alou, and J. A. Cobos, "Mode selection strategy for multi-mode power converters to minimize its differential power," 2017. IEEE-ECCE 2017

[12] R. Ramos, D. Serrano, A. J. Oliver, and J. A. Cobos, "Control of a single phase inverter with multiple modulation strategies based on plant inversion,". IEEE-ECCE 2017 